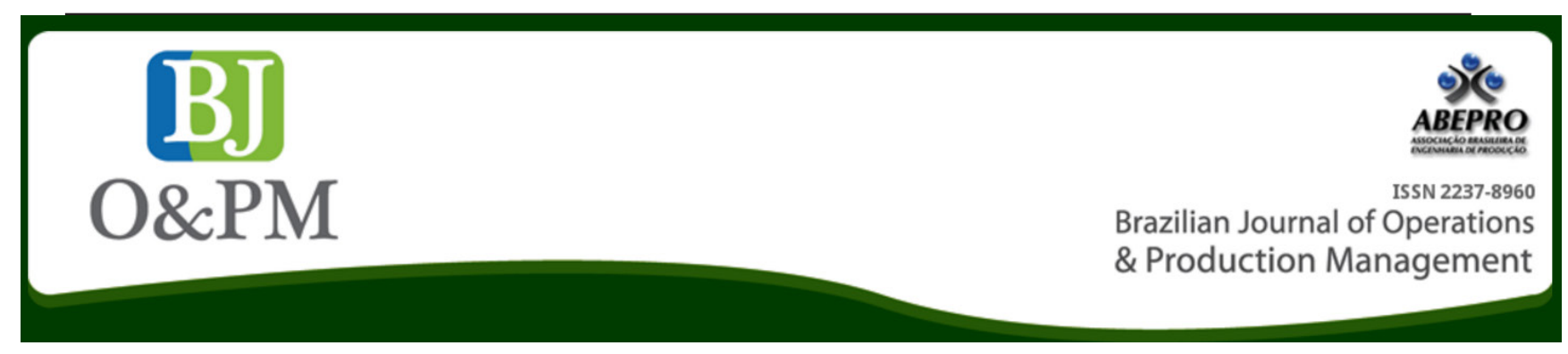

\title{
CONCEPTUAL FRAMEWORK FOR APPLYING INTERNET OF THINGS IN PRODUCTION SYSTEMS FOR SENSING ENTERPRISES
}

\author{
Andrés Bozaa; Beatriz Cortes ${ }^{\mathrm{a}}$; Maria del Mar Eva Alemanya; Llanos Cuenca ${ }^{\mathrm{a}}$ \\ ${ }^{a}$ Universidad Politecnica de Valencia (UPV) - Valência, VC, Spain
}

\section{Abstract}

Sensing Enterprise is a new concept, which appears with the Internet of Things (IoT) application in industry. This technology applied in production systems provides many benefits like better transparency or real time information. This approach proposes a conceptual framework for loT application in Production Systems. The aim of this framework is helping enterprises to identify the main elements to apply loT in Production Systems. To create this framework, a literature re-view has been made and the main components of IoT in Sensing Enterprise in production proposals have been identify. Thus, these elements and its relations have been the source for the conceptual framework proposed.

Palavras-chave: Internet of Things; Sensing Enterprise; Production System; Information System; Conceptual Framework

\section{INTRODUCTION}

According to FInES (2012) the next decade is expected to see a big change in the way enterprises operate, because to the Future Internet and the huge development achieved by enterprises in adopting new technical solutions. The FInES Cluster, in its Roadmap, proposes 9 Qualities of Being (QB) that are considered strategic for the enterprises of the future. One of these Qualities of Being is Sensing Enterprise. There is a need to decentralize intelligence, moving to a scenario where the enterprise is seen as a smart complex entity capable of sensing and reacting to (business) stimuli (FInES, 2012). This concept emerges with the evolution of IoT.

Although no universal definition exists for Internet of Things, the core concept is that everyday objects can be equipped with identifying, sensing, networking and processing capabilities, which will allow them to communicate with one another, and with other devices and services, over the Internet to achieve some useful objective (Atzori et al.,2010). Miorandi et al.,. (2012) briefly summarizes the three main system-level characteristics of the Internet-of-Things as follows: Anything communicates, anything is identified and anything interacts.

This paper focus on Sensing Enterprise and IoT applied in production systems. Thanks to the new information technologies, production processes can be optimized; the entire lifecycle of objects, from production to disposal can be monitored; and greater transparency can be gained about the status of the shop floor, the location and disposition of lots, and the status of production machines (Bandyopadhyay et Sen, 2011). Enterprises could take these advantages and improve their production system applying loT.

To this end, this paper shows key concepts to implement IoT application in Production System. Section 2 shows a literature review with the application of IoT in production; section 3 includes the conceptual framework proposed to identify and organize these key concepts; and finally, section 4 includes the conclusions drawn from this research.

\section{APPLICATIONS OF IOT IN LITERATURE}

It is possible to find useful general proposals for a wide range of industrial sectors, but also a specific proposal for 
given industrial sectors (Boza et al.,2015). For example, Cao et al., (2011) present a proposal based on loT for the toy sector, and Castro et al., (2011) for chemical industries, $\mathrm{Hu}$ et al., (2011) in the meat sector, Liu et Xu (2013) for aerospace industries and Qu et al., (2012) and Wang et Liu (2014) for the agricultural sector.

Most proposal are useful for a wide range of industrial sectors.

Cuiyun et Yuanhang (2010) study the influence of an IoT application on production and logistics in an enterprise.

Houyou et al.,(2012) design an automation system in manufacturing to support flexibility and agility in manufacturing.

Isenberg et al.,(2011) research about suitability and cooperation in collaborative production environments for autonomic and agile processes based on IoT.

Lvqing (2011) presents a mechanical production monitoring system based on loT technology.

Meyer et al., (2011) make an approach for a monitoring and control system to enable new ways in which disturbances can be dealt with in order to increase the robustness of overall plan execution.

Wang et Chen (2013) design a manufacturing inventory management model based on loT.

Yuan et al., (2013) develop a system to verify that IoT promotes workshop process visualisation developments.

Zhang et al., (2014) propose an Internet of Manufacturing Things like a tool to design an easy-to-deployment infrastructure to form a sensing manufacturing environment.

Zhiliang et al., (2013) present a project that merges Personal Digital Assistant (PDA) in manufacturing shop with IoT.

Zuehlke (2010) designs Smart Factory KL, a multi-vendor research facility for smart production technologies.

With these applications founded in literature, the main concepts to apply loT in production system have been extracted and joined to create the conceptual framework presented in this paper. These concepts allow knowing the main elements of IoT application for Sensing Enterprises in Production System.

\section{CONCEPTS OF IOT IN PRODUCTION SYSTEM}

The aim of this research is to identify and organize the key concepts to implement loT applications in Production System basing on literature review. In order to define a conceptual framework, the key concepts of loT in Sensing Enterprise and IoT in production proposals have been identified.

Thus, a conceptual framework for applying loT in Production System has been proposed.

\subsection{Internet of Things in Sensing Enterprise}

The main characteristic of Sensing Enterprise is the promptness to react in front of disturbances due to detecting events in real time with the help of new technologies, mainly loT. This is a new concept which allows any object communicates with others objects through Internet, and provide information in real time with new technologies, like RFID and sensors, to facilitate the exchange of goods and services in global supply chain networks (Gu et al.,2014; Tan et Koo, 2014; Wang, 2014; Whitmore et al.,2014).

Internet of Things is structured in three levels (Atzori et al., 2010; Bandyopadhyay et Sen, 2011; Gubbi et al., 2013; $\mathrm{Gu}$ et al.,2014; Singh, Tripathi et al.,2014). These levels provide all the elements to apply loT:

Edge level: this level is formed by the physical part of IoT. ID-technologies and Sensors below to these level (Tan et Koo, 2014). This level gives to the objects the physical part to store information and give them intelligence. This part is formed by RFID (Cao et al.,2011; Castro et al.,2011; Hu et al.,2011; Isenberg et al., 2011; Liu et Xu, 2013; Shengduo et Jian, 2012; Vossiek et al.,2010; Wang et Liu, 2014) and two dimensional code (Lee et al.,2012; Lvqing, 2011; Meyer et al.,2011; Stephan et al.,010; Zhiliang et al.,2013). For reading these ID-technologies, there are sensors et al., 2011; Hu et al.,2011; Qu et al., 2012; Vossiek et al.,2010; Zhang et et al.,2014) and cameras (Lee et al., 2012; Shengduo et Jian, 2012). There are also Object Memory Servers (Stephan et al., 2010), to store the information in each object and database servers with enterprise information (Cao et al., 2011; Cuiyun et Yuanhang, 2010; Liu et Xu, 2013; Meyer et al.,2011; Wang et Liu, 2014; Zhiliang et al.,2013).

Access Gateway Level: objects need a network to send and receive information between these. The management of these network bellows to these level. The possible networks are Wireless Sensor Network (Castro et al.,2011; Shengduo et Jian, 2012), Mobile Communication Network (Lee et al.,2012; Qu et al.,2012), GPS (Liu et Xu, 2013; Meyer et al.,2011), Bluetooth (Zuehlke, 2010), 6LoWPAN (Castro et al.,2011) and Zigbee (Zhang et al.,2014; Zuehlke, 2010).

Application Level: in this level, objects acquire intelligence through implemented software. These objects can 
communication also with an application in a computer or a smartphone. This application can be new software (Cao et al., 2011; Huet al.,2011; Lvqing, 2011; Wang et Chen, 2013; Wuest et al.,2012) or an extended part of information system in enterprise (Houyouet al.,2012; Zhiliang et al.,2013).

To sum up, Sensing Enterprises are based on Internet of Things, and loT is structured in three levels: Edge, the physical part (RFID, sensor, etc); Access, the part carried out of object communication; and Application, which can be new application or a module to extend the present information system (Figure 1).

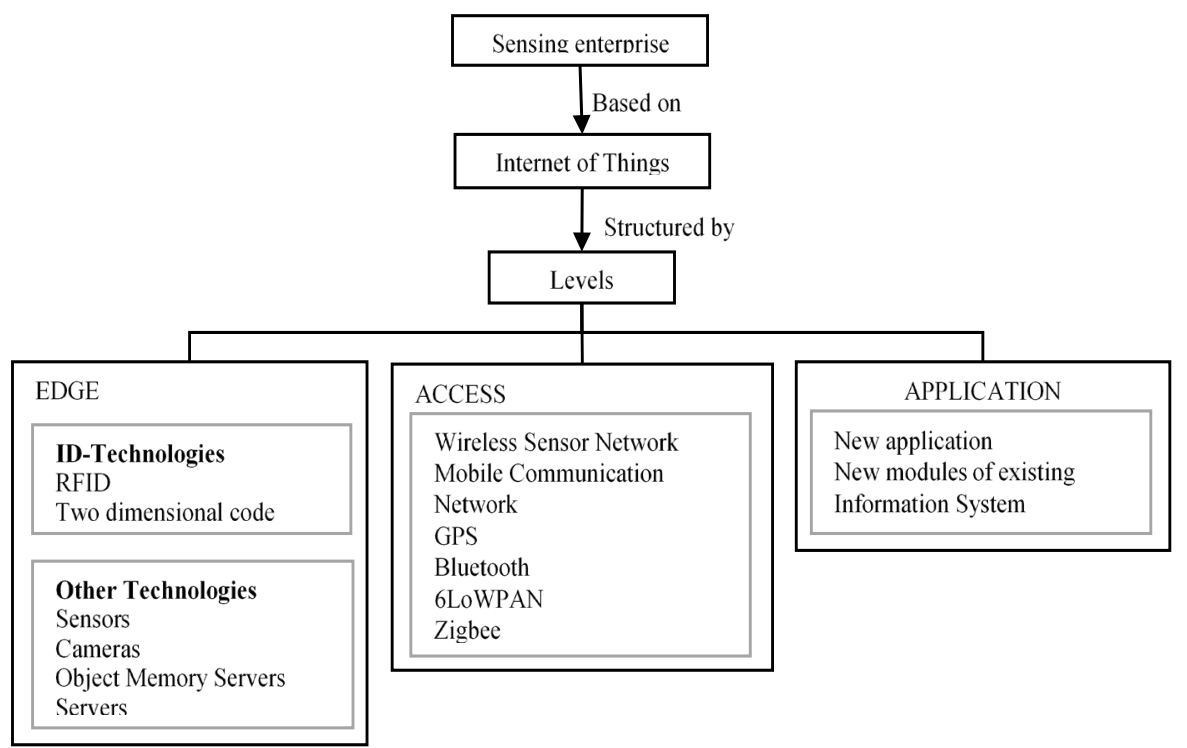

Figure 1. Main concepts of loT Application

\subsection{Internet of Things in Production Proposals}

Production system is a set of tasks to manage production in an enterprise. These tasks can be classified in three phases: Planning, Operations and Control (Cuatrecasas, 1994). To manage each phase, enterprise uses different information technologies. These technologies provide information to help managers making decisions (Simchi-Levi et al.,2003). IoT is one of these technologies which provides information (Cuiyun et Yuanhang, 2010).

In Production Planning, for example, inventory management application (Cuiyun et Yuanhang, 2010; Isenberg et al.,2011) to know the current inventory and to plan in base of this information; or tracking management system (Cuiyun etYuanhang, 2010; Wuest et al.,2012) to know the times of transporting or production and planning with this information.

In Operation Phases, IOT application allows factory automation (Houyou et al.,2012), product manufacturing workshop (Liu etXu, 2013) or mechanical production with management system (Lvqing, 2011). The applications in this phase are also called Internet of Manufacturing Things (Zhang et al.,2014; Zhiliang et al.,2013).

The largest number of IOT application in production system are for the Control Phase et al., 2015). In this phase, some applications are Resource Management Systems
(Lee et al.,2012), to control resources to accomplish the planning; Monitoring and Control Systems for disturbances in production (Meyer et al.,2011; Yuan et al.,2013); tracking systems to control the necessary pieces of a product (Qu et al.,2012); or a management systems to control the environment of production like agriculture o food factory (Hu et al.,, 2011; Shengduo et Jian, 2012).

In summary, IoT provides value information, taken from production system or other systems with relevant information for production, which enriches the Enterprise Information Systems. This information systems based on IoT improves the different phases of Production System: Planning, Operations and Control (Figure 2).

\subsection{Proposed Framework of Internet of Things in Production System}

In this section, a conceptual framework for Internet of Things Application in Production System of Sensing Enterprises is presented. Figure 3 represents the complete framework joining the concepts presented before. Sensing Enterprise has a production system that is improved with Information Systems. Information Systems are complemented by product information provided by IoT, which is structured in three levels: Edge, Access and Application. 

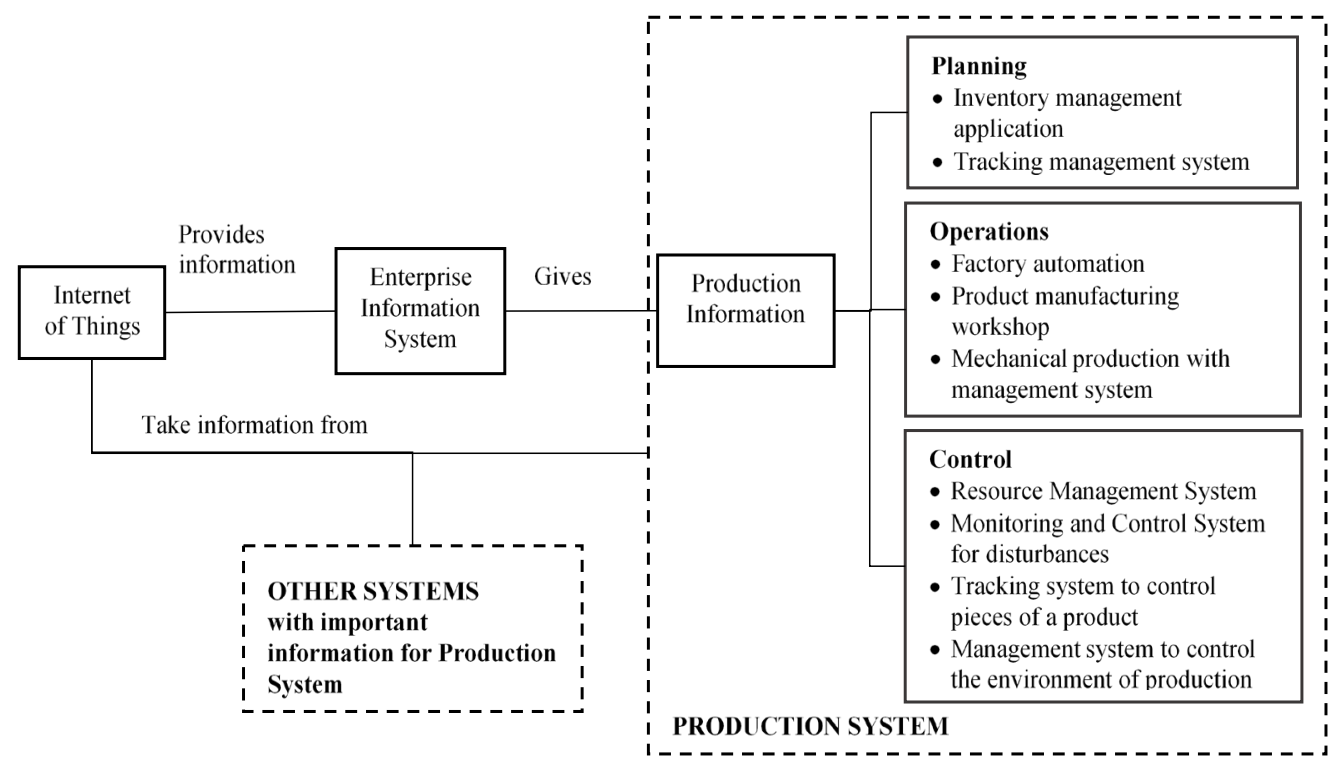

Figure 2. Main concepts of loT in Production system

Based in these concepts, enterprise have to contemplate the phase whose information must to be improved (Inventory to plan, product localization to operate, production environment to control, etc). Then, enterprise should study the elements necessary in each level of loT structure:
Application (What kind of application is required? Will the application be new or an ERP extension?), Access network (How are objects going to communicate? How many objects will be?) and Edge (What ID-technologies are objects going use? Are sensors going to be necessaries?).

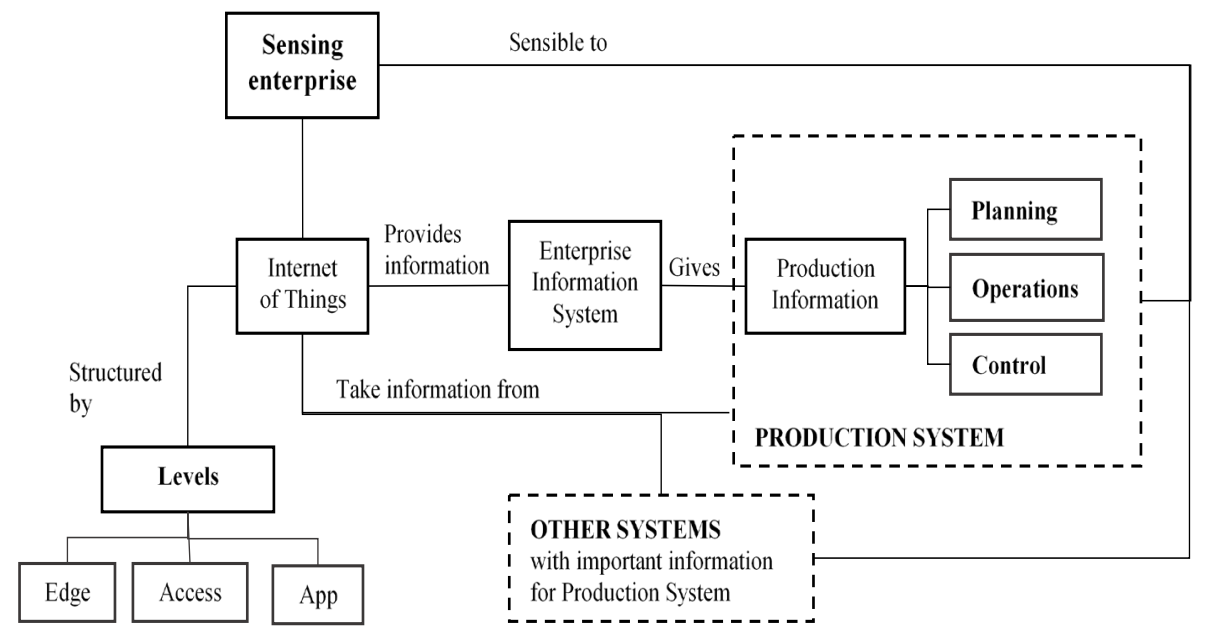

Figure 3. Conceptual Framework of IoT Application in Production System for Sensing Enterprise

\section{CONCLUSIONS}

This paper presents a conceptual framework about loT in Production system inside Sensing Enterprise. To define this framework, a literature review about loT applications in production System has been made. Even though there are few researches, main concepts of IoT applied in Production System has been extracted.
These elements help any enterprise of any sector to apply loT and show examples of applications that improve the production system in each phase. This framework intends to help enterprises to acquire sensibility in front of disturbances in the Production System. A possible future line will be proving this framework in a real company to see if these concepts help to apply loT. 


\section{REFERENCES}

Atzori, L., lera, A. and Morabito, G. (2010), "The Internet of Things: A survey", Comput. Netw., Vol.54

Bandyopadhyay, D. et Sen, J. (2011), "Internet of things: Applications and challenges in technology and standardization", Wirel. Pers. Commun., Vol.58, pp. 49-69.

Boza, A., Cortés, B., Cuenca, L. and Alarcón, F. (2015), "Internet of Things Applications in Production Systems", presented at ICEIS - 17th Int. Conf. on Enterprise Information Systems.

Cao, Y.L., Li, W.F. and Song, W. (2011), "Research on Materials Tracking in Toy Production Based on the Internet of Things" Adv. Mater. Res. 314-316, 2439-2442.

Castro, M., Guillen, A., Fuster, J.L., Jara, A.J., Zamora, M.A. and Skarmeta, A.F.G. (2011), "Oxygen Cylinders Management Architecture Based on Internet of Things", presented at ICCSA conference, pp. 271-274.

Cuatrecasas, L. (1994), “Organización y gestión de la producción en la empresa actual", CPET.

Cuiyun, M. et Yuanhang, H. (2010), "Discussion on the Application of Internet of Things in Logistics Production Management", presented at ICEE conference, pp. 39013903.

FInES (2012). "FInES research roadmap 2025: future internet enterprise systems cluster (FInES)", , available at: http://cordis.europa.eu/fp7/ict/enet/documents/finesresearch-roadmap-v30_en.pdf (Access 01/14, 2015)

Gubbi, J., Buyya, R., Marusic, S. and Palaniswami, M. (2013), "Internet of Things (IoT): A vision, architectural elements, and future directions", Future Gener. Comput. Syst., Vol. 29, pp. 1645-1660.

Gu, L., Wang, J. and Sun, B. (2014), "Trust management mechanism for Internet of Things", China Commun., Vol.11, pp. 148-156.

Houyou, A.M., Huth, H.P., Trsek, H., Kloukinas, C. and Rotondi, D. (2012), "Agile manufacturing: General challenges and an loT@Work perspective", presented at 2012 ETFA conference, pp.1-7.

Hu, T., Zheng, M. and Zhu, L. (2011), "Research Application of the Internet of Things Monitor Platform in Meat Processing Industry", presented at 2011 Int. Conf. on Human-Centric Computing and Embedded and Multimedia Computing, Lecture Notes. Springer Netherlands, pp. 165172.

Isenberg, M.-A., Werthmann, D., Morales-Kluge, E. and Scholz-Reiter, B. (2011), "The Role of the Internet of Things for Increased Autonomy and Agility in Collaborative Production Environments. Architecting the Internet of Things", Springer Berlin Heidelberg, pp. 195-228.
Lee, C.K.H., Choy, K.L., Law, K.M.Y. and Ho, G.T.S. (2012), "An intelligent system for production resources planning in Hong Kong garment industry", presented at 2012 IEEE Int. Conference on Industrial Engineering and Engineering Management, pp. 889-893.

Liu, J. et Xu, W. (2013), "Technical State Monitoring and Evaluation of Aerospace Product Manufacturing Workshop Based on Internet of Things", presented at the 2013 GreenCom, iThings/CPSCom, IEEE Int. Conference and IEEE Cyber, Physical and Social Computing.

Lvqing, Y. (2011), "The analysis and design of machinery production monitoring system based on Internet of Things", presented at the 2011 Int. Conference on Electronics, Communications and Control (ICECC), pp. 3980-3983.

Meyer, G.G. Hans Wortmann, J.C. and Szirbik, N.B., (2011), "Production monitoring and control with intelligent products", International Journal of Production Research, Vol.49, pp. 1303-1317.

Miorandi, D., Sicari, S., De Pellegrini, F. and Chlamtac, I. (2012), "Internet of things: Vision, applications and research challenges", Ad Hoc Netw. Vol. 10, pp. 1497-1516.

Qu, B., Jing, X., Wang, X., Li, Y. and Liang, Y. (2012), "Design on Cucumber Traceability System Based on the Internet of Things", Computer and Computing Technologies in Agriculture V, IFIP Advances in Information and Communication Technology. Springer Berlin Heidelberg.

Shengduo, L. et Jian, Z. (2012), "Research and Development of Management Platform for Precision Ecological Agriculture Based on the Internet of Things", Software Engineering and Knowledge Engineering: Theory and Practice, Springer Berlin Heidelberg, pp. 387-393.

Simchi-Levi, D., Kaminsky, P. and Simchi-Levi, E. (2003), "Designing and Managing the Supply Chain" Ed. McGrawHill.

Singh, D., Tripathi, G. and Jara, A.J. (2014), "A survey of Internet-of-Things: Future vision, architecture, challenges and services", IEEE World Forum on Internet of Things 2014, pp. 287-292.

Stephan, P., Meixner, G., Koessling, H., Floerchinger, F. and Ollinger, L. (2010), "Product-mediated communication through digital object memories in heterogeneous value chains", 2010 PerCom.

Tan, J. et Koo, S.G.M. (2014), "A survey of technologies in internet of things", 9th IEEE Int. Conference on Distributed Computing in Sensor Systems, DCOSS 2014, IEEE Computer Society.

Wang, H. et Chen, X. (2013), "Internet of Things Technology-Based Manufacturing Inventory Management" 2013 Int. Workshop on Computer Science in Sports. Atlantis Press. 
Wang, X.F. (2014), "Research on security issues of the internet of things", presented at the 4th Int. Conference on Materials Science and Information Technology, MSIT 2014, pp. 4261-4264.

Wang, X. et Liu, N. (2014), "The application of internet of things in agricultural means of production supply chain management", J. Chem. Pharm. Res., Vol. 6, pp. 2304-2310.

Whitmore, A., Agarwal, A. and Da Xu, L. (2014), "The Internet of Things-A survey of topics and trends", Inf. Syst. Front. pp. 1-14.

Yuan, L., Guo, Y., Jiang, J. and Nian, L. (2013), "The Research on Monitoring of Discrete Manufacturing Process Based on Internet of Things", GreenCom, 2013 iThings/ CPSCom, pp. 1186-1191.

Zhang, Y., Wang, W., Liu, S. and Xie, G. (2014), "RealTime Shop-Floor Production Performance Analysis Method for the Internet of Manufacturing Things", Adv. Mech. Eng. 2014, e270749.

Zhiliang, F., Xin, W., Guangrong, Y. and Tao, D. (2013), "PDA-Based Application and Research for Workshop Internet of Things",GreenCom, 2013 iThings/CPSCom.

Zuehlke, D. (2010), "SmartFactory-Towards a factory-ofthings", Annu. Rev. Control 34. 